\title{
O processo de formação didático-pedagógica em saúde: aprendizagens percebidas na voz dos pós-graduandos
}

\author{
The process of didatic-pedagogical training in health: \\ learning perceived in the voice of postgraduate students
}

Patricia Lima Dubeux Abensur ${ }^{1}$, Gabrielle Passarini Mendes de Carvalho', Lidia Ruiz-Moreno ${ }^{1}$

\begin{abstract}
RESUMO
Introdução: O presente estudo integra o projeto "Formação de professor: estratégia dialógica problematizadora com uso de ambiente virtual de aprendizagem", desenvolvido na disciplina de Formação Didático Pedagógica em Saúde (FDPS), ofertada pelo Centro de Desenvolvimento do Ensino Superior em Saúde (CEDESS) da Universidade Federal de São Paulo (UNIFESP), no formato bimodal (presencial e a distância). Objetivo: Analisar as aprendizagens construídas pelos pós-graduandos no processo de formação docente ao longo da disciplina FDPS. Métodos: Os sujeitos da pesquisa foram onze profissionais de diversas áreas da saúde. Para a coleta de dados, foi solicitada a cada pós-graduando, antes do início da disciplina, uma carta de apresentação, manifestando as suas expectativas e, ao término da disciplina, uma autoavaliação, sobre as aprendizagens construídas durante o processo. A análise temática partiu dos seguintes núcleos orientadores: expectativas Iniciais, aprendizagens construídas e perspectivas futuras na docência. Resultados: A maioria dos participantes manifestou a intenção de conhecer técnicas de transmissão de conteúdos com centralidade no docente, em menor proporção também foi expresso o desejo de compartilhar informações e refletir sobre o cenário da educação e da saúde no país. No núcleo, aprendizagens construídas, os pós-graduandos valorizaram as estratégias utilizadas no decorrer da disciplina, destacando a construção e apresentação do planejamento educacional em grupos multiprofissionais. Nas perspectivas futuras, muitos demonstraram o reconhecimento de continuar sua formação docente para melhor exercício da profissão. Conclusão: A educação permanente do processo de formação docente parece ser uma demanda crescente, o que valoriza essa atividade e sua profissionalização.
\end{abstract}

Palavras-chave: saúde; educação; ensino; educação superior.

\begin{abstract}
Introduction: This study is part of the project "Teacher training: problem-dialogical strategy with virtual environment use of learning" developed in the discipline Didatic-Pedagogical Training in Health (DPTH), offered by the Higher Education Development Center on Health (CEDESS) in the Federal University of São Paulo (UNIFESP), in bimodal format (presence and distance). Objective: To analyze the learning built by graduate students in the teacher education process throughout DPTH discipline. Methods: The subjects of the research were eleven professionals from different areas of health. For the data collect, was requested to every postgraduate student, before the start of the course, an introduction letter, expressing their expectations and, in the end of the discipline, a self-assessment of the learning built during the process. The thematic analysis came from the following guiding cores: initial expectations, learning built and future perspectives. Results: The expectations had manifested the intention to know techniques and tools to transmit the contents with centrality in the teacher, but even in minor proportion, was also expressed a desire to share information and reflect the education and health scenario in the country. In the core learning built, the students appreciated the strategies used in the discipline, emphasizing the construction and presentation of an education planning in small multiprofessional groups. In the future perspectives, many had shown the recognition to continue their teacher training to a better practice of the profession. Conclusion: the continuing education of the teacher training process appears to be a growing demand, which values this activity and its professionalisation.
\end{abstract}

Keywords: health; education; teaching; education, higher.

Recebido em: 12/07/2015

Revisado em: 28/08/2015

Aprovado em: 08/09/2015

Autor para correspondência: Patricia Lima Dubeux Abensur - Rua Pedro de Toledo, 859 - Vila Clementino - CEP: 04039-032 - São Paulo (SP), Brasil E-mail: patricia.abensur@unifesp.br

Fonte de financiamento: CNPq, CAPES (Programa Pró-Ensino na Saúde)

Conflito de interesses: nada a declarar. 


\section{INTRODUÇÃO}

Este artigo apresenta um recorte do projeto "Formação de professor: estratégia dialógica problematizadora com uso de ambiente virtual de aprendizagem", desenvolvido no âmbito da Universidade Federal de São Paulo (UNIFESP), em parceria com a Universidade de Córdoba (UNC) e Universidade Nacional de Rio Cuarto (UNRC), da Argentina.

Esse projeto teve como objetivo planejar, implementar, sistematizar e analisar o processo de formação de professores na disciplina "Formação Didático-pedagógica em Saúde", numa proposta bimodal com a utilização da estratégia de Indagação Dialógica Problematizadora (IDP), a qual está fundamentada nas concepções construtivistas por considerar que a construção e reconstrução do conhecimento em sala de aula requer uma troca constante entre os participantes do processo e entre eles e o conhecimento ${ }^{1}$.

A proposta educativa se inscreve no contexto da educação superior em saúde, no qual mudanças no que se refere a questões didático-pedagógicas vem sendo sentidas mais fortemente a partir da implantação do Sistema Único de Saúde (SUS) (Lei 8.080/1990)² e das Diretrizes Curriculares Nacionais $(\mathrm{DCN})^{3}$. Ambos orientam o desenvolvimento de um currículo que privilegie as necessidades de saúde da realidade na qual o curso se insere, com o objetivo de fortalecer o nosso sistema de saúde pública.

Paulo Freire ${ }^{4}$ lembra-nos que não se pode pensar em realizar mudanças no ensino ou no currículo sem pensar na formação dos professores que irão concretizar em sala de aula essas mudanças.

Algumas iniciativas e experiências na área da saúde aparecem como possibilidades de formação atendendo as mudanças políticas e sociais e trazem para discussão a importância do estágio de docência na graduação, a utilização de estratégias dialógicas problematizadoras e o planejamento integrado na formação docente $e^{5-7}$.

Destaca-se, nessas iniciativas, a contribuição para a familiarização com a função docente e a realidade da graduação, bem como o desenvolvimento de uma prática educativa, como espaço de formação continuada, reflexivo e coletivo, no que se refere ao planejamento integrado.

No entanto, prevalece na maioria das instituições de ensino superior uma cultura acadêmica na qual a formação do professor universitário se sustenta na pesquisa e uma prática docente que carrega concepções de aprendizagem de transmissão-recepção do conhecimento, revelando a opção por um modelo de ensino tradicional ${ }^{8,9}$.

Outro estudo sobre a docência universitária na saúde alerta sobre o desafio de superar práticas tradicionais de ensino que dificultam a formação de egressos com perfil profissional diferenciado e em sintonia com o que preconizam as novas DCN e o SUS ${ }^{10}$.

Acredita-se que ser professor é uma das atividades mais complexas do ser humano, uma vez que implica em propiciar a apropriação crítica e significativa do conhecimento construído historicamente como mediação para a formação de uma consciência cidadã para a construção de uma sociedade digna, solidária e justa para todos ${ }^{11}$.

Nesse sentido, a docência enquanto atividade profissional exige preparação e formação para o seu pleno desenvolvimento. Garcia $^{12}$ defende que,

Parece-nos claro que o ensino, a docência, se considerada uma profissão, é necessário, tal como noutras profissões, assegurar que as pessoas que a exercem tenham um domínio adequado da ciência, técnica e arte da mesma, ou seja, possuam competência profissional.

Para ensinar, o domínio do conhecimento especifico é condição necessária, mas não suficiente. O exercício da docência exige múltiplos saberes que precisam ser apropriados e compreendidos em suas relações.

Zanchet e Fagundes ${ }^{8}$, em pesquisa recente, destacam que

É necessário compreender a docência como uma profissão que exige um conhecimento aprofundado do conteúdo específico, entretanto, mostra que é importante existir interlocução entre os conhecimentos técnicos das especialidades com os conhecimentos pedagógicos.

O desenvolvimento da função docente universitária na área da saúde exige preparação numa perspectiva teórica e prática que possibilite uma reflexão ampliada sobre o contexto e a realidade das políticas da saúde e da educação superior no país.

Sabe-se que algumas Instituições de Ensino Superior, como é o caso da Universidade Federal de São Paulo, ofertam na pós-graduação stricto sensu disciplinas com caráter didático-pedagógico como uma estratégia para sensibilizar o futuro docente da educação superior para a necessidade de formar-se para o exercício da docência. O que atende a orientação da Lei de Diretrizes e Bases da Educação Nacional — Lei 9.394/96 ${ }^{13}$ - , artigo 66, que expressa: "a preparação para o exercício do magistério superior far-se-á em nível de pós-graduação, prioritariamente em programas de mestrado e doutorado".

Defende-se que a formação didático-pedagógica parta do princípio de que a função docente não significa apenas a instrumentação técnica, mas uma reflexão crítica desta prática e da realidade onde se realiza. É preciso, então, discutir sobre o significado e sentido da função docente universitária, tomando a prática e a experiência vivenciada como ponto de partida para refletir em torno dos saberes necessários para o desenvolvimento dessa prática.

Diante disto, o presente artigo teve como objetivo analisar as aprendizagens construídas pelos pós-graduandos no processo de formação docente ao longo da disciplina de Formação Didático Pedagógica em Saúde, a partir das narrativas produzidas no início e no término do curso. 


\section{MÉTODOS}

A presente pesquisa de abordagem qualitativa teve como cenário a disciplina de "Formação Didático-pedagógica em Saúde", ofertada pelo Centro de Desenvolvimento do Ensino Superior em Saúde da Universidade Federal de São Paulo (CEDESS/UNIFESP), aos pós-graduandos da área da saúde dos cursos stricto sensu, no formato bimodal (presencial e ambiente virtual de aprendizagem Moodle), com carga horária total de 60 horas. A disciplina teve a finalidade de propiciar uma formação docente integrada à realidade sócio-política brasileira e às atuais políticas de Educação e Saúde vigentes no país. Dentre os conteúdos trabalhados destacam-se o Sistema Educacional Brasileiro, Políticas Públicas de Educação e Saúde, Currículo, Tendências Pedagógicas, Estratégias de ensino, aprendizagem e avaliação. As estratégias utilizadas consistiram entre outras em aula expositiva dialogada, mesa redonda, trabalhos em pequenos grupos, fórum de discussão, narrativas.

Do conjunto de atividades desenvolvidas na disciplina, foram escolhidas para este trabalho, as narrativas elaboradas pelos pós-graduandos na etapa inicial e final da disciplina (Figura 1), no sentido de analisar as aprendizagens construídas durante o processo.

Participaram da disciplina 33 pós-graduandos, dentre os quais foram selecionados aleatoriamente para esse estudo, onze profissionais das seguintes áreas da saúde: Biomedicina, Ciências

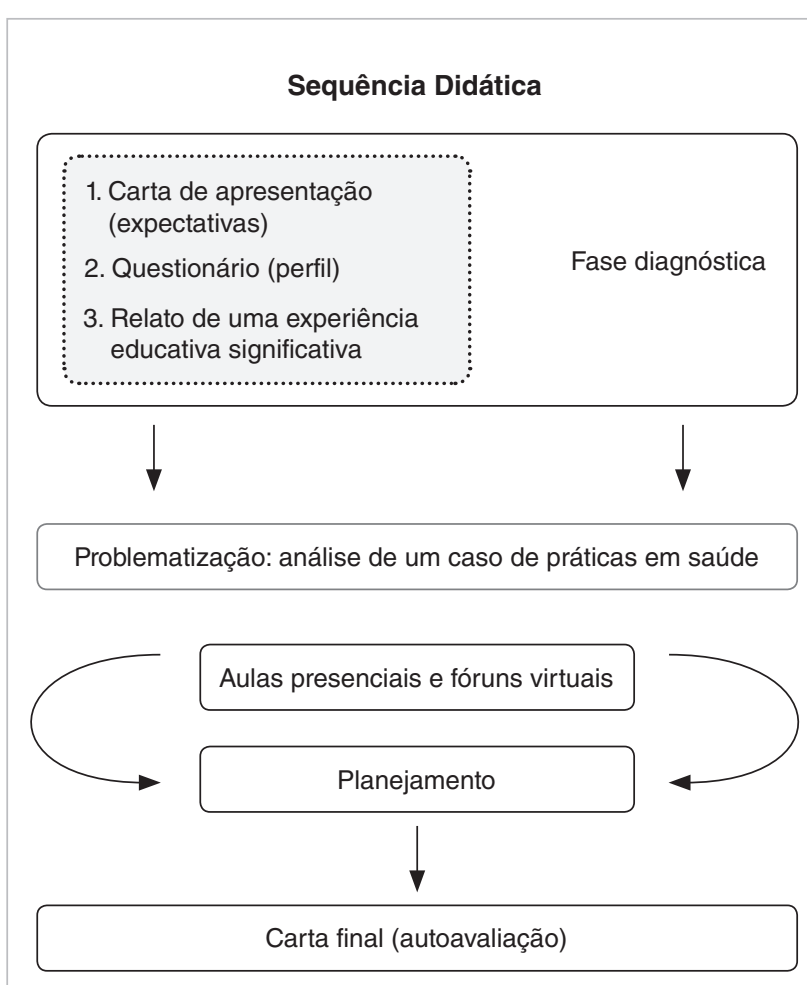

Figura 1: Sequência didática da disciplina Formação Didático pedagógica em Saúde oferecida pelo Centro de Desenvolvimento do Ensino Superior em Saúde da Universidade Federal de São Paulo
Biológicas, Educação Física, Enfermagem, Farmácia, Fisioterapia, Medicina, Veterinária, Nutrição, Psicologia e Química.

Utilizou-se como técnica de análise de dados, a análise temática. Segundo Bardin ${ }^{14}$, a análise temática é uma forma de investigação que melhor se adequa aos dados qualitativos e consiste em três etapas: pré-análise, exploração do material e tratamento dos resultados e interpretação para analisar os dados obtidos, propondo inferências e interpretações respondendo aos objetivos propostos.

Dessa forma, procedeu-se a leitura, seleção e organização do material numa planilha Excel, de acordo com os núcleos orientadores: expectativas iniciais, aprendizagens construídas e perspectivas futuras para a docência.

\section{RESULTADOS E DISCUSSÃO}

A maioria das expectativas iniciais esteve centrada em aprendizagens de técnicas de apresentação de conteúdos, o que pressupõe a centralidade na figura do professor, como destacado nas falas a seguir:

Espero nesse curso conseguir aprender mais mecanismos e técnicas sobre como disseminar o conhecimento na área da saúde. (Veterinária)

Espero aprimorar meus conhecimentos e aprender técnicas didáticas. Saber ensinar e passar meus conhecimentos na sala de aula. (Fisioterapeuta)

Em menor proporção, também foram identificadas expectativas relacionadas à troca de experiências e formação crítico-reflexiva, considerando o contexto político e econômico, conforme trechos abaixo:

Neste curso que agora ingresso, vislumbro a possibilidade de manter minha formação continuada na docência e na troca de experiências com os professores, poder agregar conhecimentos que contribuam com os desafios impostos na atualidade ao professor nas IES. Como lidar com a formação que visa nichos de mercado e pautada numa lógica capitalista, de acúmulo de informações e pouca preocupação com a aquisição de competências e habilidades pertinentes ao papel profissional, ou mesmo seu compromisso social. (Enfermeira)

No espaço de formação didático-pedagógica em saúde, espero aprender com a experiência dos colegas que vem atuando como professor. (Nutricionista)

Percebe-se que a expectativa inicial estava centrada na aprendizagem de técnicas para transmitir conhecimentos, com centralidade no professor, o que na conceituação definida por Mizukami ${ }^{15}$ integra as características de uma abordagem pedagógica tradicional. No entanto, os pós-graduandos também trouxeram 
expectativas relacionadas a uma abordagem cognitivista ${ }^{15}$ que valoriza a interação com o outro e a troca de experiências.

Nas narrativas de autoavaliação finais, percebeu-se a valorização por parte dos pós-graduandos do modelo pedagógico utilizado durante a disciplina, que buscava privilegiar a interação e troca de experiências entre os pós-graduandos e também a equipe docente, conforme ressaltado a seguir:

No aspecto pessoal, eu pude aprender que é possível obter trocas muito ricas entre diferentes pessoas, de diferentes locais. (Psicóloga)

Esperava do curso conteúdos didáticos para aulas, postura profissional, técnicas para dar aulas, maneiras didático-pedagógicas; no entanto, o conteúdo abordado e a forma que foi abordado será muito importante para qualquer outro planejamento e objetivo que tivermos na vida, ou seja, contribuiu tanto para o crescimento profissional como individual. (Fisioterapeuta)

Devido à abertura da equipe docente em sempre querer saber a nossa opinião sobre assuntos discutidos antes de qualquer início de aula, tornaram as aulas mais interativas, fazendo com que quiséssemos estar lá e não apenas 'estar lá por estar'. Com isso, a interação entre os alunos foi se aproximando. (Bióloga)

Há o reconhecimento pelos participantes da importância tanto da equipe docente quanto do grupo discente no processo de ensino-aprendizagem, no qual os conteúdos trabalhados extrapolaram a dimensão técnica e alçaram tanto a dimensão pessoal como a profissional. De acordo com Freire ${ }^{16}$,

O professor de quem a sociedade brasileira precisa no hoje de seu trânsito há de ser aquele que jamais se deleite com sua «sabedoria», às vezes inautenticamente livresca, apresentada em aulas que funcionam quase como se fossem cantigas de ninar. O seu papel há de ser outro. [...] Ou adere ao diálogo criador e comunica ou se minimiza como simples veículo de ingênuos e inoperantes comunicados. Ou se julga humildemente um companheiro de seu estudante, a quem ajuda a ajudar-se na busca de conhecimento, com quem também busca esse conhecimento ou corre o risco de seu esvaziamento.

Os encontros propiciaram momentos de trocas de conhecimentos e integração entre os conhecimentos teóricos e práticos, a partir da utilização de variadas estratégias interativas e colaborativas tanto no espaço presencial como a distância, conforme descrito abaixo.

No aspecto profissional, eu aprendi muito com os métodos e abordagens utilizados pelas professoras e convidados, os quais propiciavam de uma maneira voluntária a participação em sala de aula, mas também valorizavam o ensino à distância. (Psicóloga)
Conteúdos e a forma que estes foram abordados foram de grande importância para o desenvolvimento profissional como futuro docente, preparo para exercer a arte de ensinar, com uma interação ensino-serviço. (Fisioterapeuta)

A discussão no formato de mesa redonda fechou a aula com chave de ouro. Quando recebemos dois médicos convidados para fazerem o relato da experiência deles dentro desta integração ensino-serviço, foi também um momento muito enriquecedor. (Nutricionista)

Vê-se que é possível, desde que com planejamento, utilizar diversidade de estratégias variadas e possibilitar a participação ativa de todos no processo de formação. Sobre a importância do uso e da escolha das estratégias no decorrer de um curso, Masetto ${ }^{17}$ esclarece que:

as estratégias para a aprendizagem constituem-se em uma arte de decidir sobre um conjunto de disposições que favoreçam o alcance dos objetivos educacionais pelo aprendiz, desde a organização do espaço sala de aula com suas carteiras até a preparação do material a ser empregado, como recursos audiovisuais, visitas técnicas, internet etc., ou uso de dinâmicas de grupo ou outras atividades individuais.

Durante o processo educativo, os participantes em pequenos grupos multiprofissionais desenvolvem um planejamento, tanto em momentos presenciais como a distância. As vivências e conteúdos trabalhados durante a experiência servem de subsidio para essa construção, como destacado na fala dos pós-graduandos:

Até mesmo a defesa do seu planejamento educacional, que foi um dos momentos onde percebemos o retorno e amadurecimento de tudo aquilo que foi manifestado durante o curso e que vimos o crescimento de cada aluno como formador da ideia que no futuro possivelmente possa vir a fazer parte do seu dia a dia. (Biomédico)

Todos nós pudemos criar e utilizar de muitas estratégias de ensino que até então muitas eu não conhecia e pude ter o contato; por isso, foi muito proveitoso mergulhar de cabeça nesta atividade (planejamento educacional) para absorver o máximo de conceitos que poderíamos obter perante a confecção do documento teórico-prático. (Biomédico)

Um momento interessante da disciplina foi o planejamento em grupo, através do fórum do Moodle. Normalmente, pensamos que tarefas em grupo somente funcionam quando todos os participantes estão presentes e em muitos encontros. Porém, este planejamento me mostrou que é possível colaborar em grupo mesmo à distância. (Médico) 
O processo de planejamento foi iniciado a partir de uma situação-problema extraída da realidade da educação e da saúde como um desafio a ser enfrentado pelos pós-graduandos. Essa situação tratava de uma proposta de reorganização curricular de um curso de medicina em uma instituição de educação superior, que previa a inserção dos alunos de graduação, já nos anos iniciais, em unidades de saúde da família com o objetivo de estimular a articulação ensino-serviço desses profissionais conforme as Diretrizes Curriculares Nacionais (DCN). A partir da apresentação dessa situação problema, cada um dos grupos deveria desenvolver um planejamento educacional em resposta à situação apresentada, a qual gerava resistência tanto por parte dos discentes quanto dos docentes e preceptores. Procurou-se com os conteúdos desenvolvidos no decorrer na disciplina subsidiar e possibilitar a compreensão e o aprofundamento em nível mais elaborado dessa realidade com o objetivo de que os pós-graduandos propusessem ações viáveis e tangíveis para o problema apresentado ${ }^{18}$.

A questão profissional bem como a integração multiprofissional esteve presente nas autoavaliações dos pós-graduandos.

Pude conhecer melhor as outras áreas [da saúde] e pude julgar, analisar e respeitar melhor seus programas (curriculares). (Química)

Passamos a fazer parte dos [Núcleos de Apoio à Saúde da Família] NASFs em outubro de 2011. Por ser algo novo, eu mesma não sabia exatamente como eu poderia colaborar com a saúde populacional, mas com o curso tudo ficou esclarecido. Sei que nunca mais olharei para a minha profissão da mesma maneira. (Veterinária)

O enriquecimento tanto pessoal quanto profissional é incontestável e visível durante as discussões, que em minha opinião são os melhores momentos do curso, pois é onde podemos conhecer as experiências de nossos colegas de acordo com sua opinião. (Farmacêutica)

Acredito que essa interação multiprofissional é muito importante tanto na vida pessoal como social. Todos saem ganhando com essas experiências e isso ainda não encontrei em nenhuma das outras disciplinas. (Bióloga)

O caráter multiprofissional da disciplina, com ênfase no trabalho em grupo, acaba diminuindo a fragmentação das diversas áreas do cuidado em saúde e possibilitando trocas e experiências mais ricas, que não se baseia apenas na especialidade de cada um, mas que esta seja complementar como experiência para seus pares. De acordo com Mizukami ${ }^{15}$,

O trabalho em grupo, a discussão deliberada em comum, não só é condição para o desenvolvimento mental individual, para a autonomia dos indivíduos, como também o é para a superação do egocentrismo natural do comportamento humano, que só ocorre quando há conflitos provenientes de interesses diferentes dos indivíduos.

A dimensão político-social que integrou as discussões dos conteúdos trabalhados no curso também foi reconhecida e valorizada pelos participantes.

No aspecto profissional, aprendi muito em relação às políticas de saúde brasileiras. (Médico)

O aprendizado foi mais um reforço da necessidade de pôr em prática as diretrizes no SUS de uma maneira efetiva. (Psicóloga)

Pude descobrir mais sobre as diferentes profissões da área da saúde, as suas diretrizes e como a formação na área da saúde está se atualizando e tentando preparar profissionais menos individualistas e mais humanistas, inserção de todas elas no Sistema Único de Saúde, ajudando na prevenção, na promoção da saúde. (Educação Física)

As políticas públicas e o Sistema Único de Saúde (SUS) visam minimizar a centralização do modelo biomédico, onde a ênfase é a questão anatomo-fisiológica do corpo humano e se aproximar da concepção de que existem outros saberes que contribuem para a complexidade do ser humano, para produzir um cuidado mais amplo.

Dentro deste contexto, os docentes responsáveis pela disciplina abordaram assuntos que envolveram políticas como o SUS, o Pró-saúde e o Pet-saúde com olhar crítico, contribuindo para uma visão mais humanizada e menos hospitalocêntrica dos pós-graduandos, que são colocados como sujeitos centrais e ativos no processo de ensino-aprendizagem, com ênfase na importância do diálogo, o que possibilita a troca de experiências, a interação entre as áreas da saúde e a construção de conhecimento.

Nas perspectivas, presentes na carta de autoavaliação, muitos pós-graduandos relataram o quanto a disciplina estimulou a inserção e a continuidade na atuação docente e a busca maior pelo conhecimento na área sinalizando um processo de profissionalização.

Foi uma disciplina ótima de cursar. Não a imaginava antes deste jeito que foi. Pensei que iríamos aprender como dar aula. Aprender mais sobre o que estar por trás de uma aula, a política de ensino, o planejamento educacional e qual é o momento da educação que estamos vivendo foi ainda mais importante. (Nutricionista)

Após esta disciplina, tive o desejo de me aprofundar um pouco mais em tecnologias e inovações relacionadas à apresentação de trabalhos, como apresentar de uma maneira descontraída e não cansativa o conteúdo. (Psicóloga)

Ao mesmo tempo em que saio do curso mais confiante e mais completa, também percebo o quanto ainda posso buscar de 
conhecimento e quantas técnicas e abordagens de ensino devem existir. (Veterinária)

Reconhecer a necessidade de aprofundamento e continuidade nos estudos sobre a docência é reconhecê-la como uma atividade profissional que exige formação permanentemente, pois segundo Freire ${ }^{4}$

Ninguém começa a ser educador numa certa terça-feira as quatro a tarde. Ninguém nasce educador ou marcado para ser educador. A gente se faz educador, a gente se forma, como educador, permanentemente, na prática e na reflexão sobre a prática.

Percebeu-se que as expectativas iniciais dos pós-graduandos sobre a docência refletiram o modelo pedagógico tradicional, possivelmente, vivenciado durante a graduação pela maioria dos alunos, mas essas concepções foram questionadas no decorrer da disciplina, por meio das atividades e estratégias diversificadas que exigiram uma postura ativa dos pós-graduandos e possibilitaram a ampliação do conhecimento sobre o processo de ensino-aprendizagem contribuindo com um processo formativo em sintonia com as atuais demandas sociais.
Nas falas trazidas ao longo do texto, notou-se que entre as estratégias mais valorizadas pelos pós-graduandos situam-se os debates com profissionais convidados que atuam na atenção básica no Programa de Saúde da Família, discussões e reflexões sobre as atuais políticas públicas de educação e saúde, o desenvolvimento e apresentação do planejamento educacional realizado em grupos multiprofissionais, bem como a diversidade de estratégias utilizadas durante os encontros presenciais e a distância.

Destaca-se a atividade do planejamento que, segundo os relatos, foi um dos momentos mais significativos para a construção do conhecimento compartilhado durante a disciplina.

Deixa-nos esperançosos as perspectivas em relação a demanda de educação permanente do processo de formação docente, valorizando essa atividade e sua profissionalização.

\section{AGRADECIMENTOS}

Contamos com a colaboração do Designer Instrucional Antonio Aleixo da Silva do Departamento de Informática em Saúde (DIS/ UNIFESP), responsável pelo planejamento e estruturação da página no Moodle; coordenação do módulo de aproximação ao ambiente Moodle; e suporte técnico.

\section{REFERÊNCIAS}

1. De Longhi AL, Bermudez GMA, Abensur PLD, Ruiz-Moreno L. Una estrategia didáctica para la formación de educadores de salud en Brasil: la indagación dialógica problematizadora. Interface (Botucatu). 2014;18(51):759-69. http://dx.doi.org/10.1590/1807-57622013.0967

2. Brasil. Presidência da República. Lei 8.080 , de 19 de setembro de 1990. Disponível em: http://www.planalto.gov.br/ccivil_03/leis/ I8080.htm. Acesso em: 13 jul. 2015

3. Brasil. Ministério da Educação. Conselho Nacional de Educação. Diretrizes curriculares: curso de graduação. Disponível em: http:// portal.mec.gov.br/index.php?option=com_content\&view=article\& id $=12991$ \&ltemid=866. Acesso em: 13 jul. 2015 .

4. Freire P. Educação na cidade. 5. ed. São Paulo: Cortez; 2001; p.144.

5. Ajzen C. Indagação dialógica problematizadora na formação didático pedagógica em saúde. Dissertação (Mestrado em Ensino em Ciências da Saúde) - Universidade Federal de São Paulo. São Paulo: 2011

6. Ribeiro GM. Estágio de docência na graduação: possibilidades e limites na formação de professores universitários. Dissertação (Mestrado em Educação) - Universidade Federal de Pelotas. Pelotas: 2012.

7. Souza LHF. O planejamento integrado como espaço de formação continuada do docente da Educação Superior. Dissertação (Mestrado em Educação) - Universidade Federal de Santa Catarina. Florianópolis: 2012.

8. Zanchet BMA, Fagundes MV. A preparação para o exercício do magistério superior far-se-á em nível de pós-graduação? Os docentes iniciantes respondem. Rev E-curriculum. 2012;8(1):1-21.
9. Oda WY. A docência universitária em biologia e suas relações com a realidade das metrópoles amazônicas. Tese (Doutorado em Educação Científica e Tecnológica) - Universidade Federal de Santa Catarina. Florianópolis: 2012.

10. Goncalves M. Aprender a ensinar em saúde: um estudo qualitativo em um curso de Fisioterapia. Dissertação (Mestrado em Saúde Coletiva) - Universidade Federal Fluminense. Niterói: 2011.

11. Vasconcellos CS. Competência docente na perspectiva de Paulo Freire. Rev Educ AEC. 2007;143:66-78.

12. Garcia CM. Formação de professores para uma mudança educativa. Portugal: Porto Editora, 1999.

13. Brasil. Senado Federal. Lei no 9.394, de 20 de dezembro de 1996. Estabelece as diretrizes e Bases da Educação Nacional. Diário Oficial da União. Brasília: 2005.

14. Bardin L. Análise de conteúdo. Lisboa: Edições 70; 1977.

15. Mizukami MGN. Ensino: as abordagens do processo. Reimpressão. São Paulo: EPU; 2013.

16. Freire P. O professor universitário como educador. Estudos Universitários. Rev Cultura Univ Recife. 1962;1:45-7.

17. Masetto MT. Competência pedagógica do professor universitário. 2 ed. São Paulo: Summus; 2012.

18. Abensur PLD, Monteiro ACR, Ruiz-Moreno L. Formação didático-pedagógica em saúde: a contribuição do sistema de análise de interações contingentes num fórum de discussão virtual. In: Pereira EMA (Org.). Inovações Curriculares: experiências no ensino superior com foco na interdisciplinaridade. Campinas: Unicamp; 2014. 